\title{
Graphene Layer Control Enabled by Nickel-Copper Alloy Thin Film Catalyst
}

\author{
Brendan Coyne ${ }^{1}$, Otto Zietz ${ }^{1}$, Samuel Olson ${ }^{1}$ and Jun Jiao ${ }^{1}$
}

${ }^{1 .}$ Department of Mechanical \& Materials Engineering, Portland State University, Portland, OR.

Graphene is highly desirable for its wide-ranging material properties, however current synthesis requirements present challenges for many industrial applications. The focus of this study is to utilize metal alloy catalysts to produce graphene films with reduced catalyst thicknesses at lower temperatures. The increased catalytic ability of $\mathrm{Ni}$, compared to $\mathrm{Cu}$, has been shown to reduce synthesis temperature requirements, though graphene layer number control is difficult due to increased carbon solubility. Previously, $150 \mathrm{~nm}$ bimetallic catalysts $(\mathrm{Cu} / \mathrm{Ni}$ and $\mathrm{Au} / \mathrm{Ni})$ were shown to enable mono-/few-layer graphene growth at $600{ }^{\circ} \mathrm{C}$ [1]. More recently, a theoretical study of graphene on Ni/Cu alloys concluded that improved layer number control may be achievable through adjusting the $\mathrm{Cu}$ content of the alloys [2]. Our experimental results suggest that thin film alloy catalysts can enable synthesis of continuous and primarily bi-/few-layer graphene films at $500{ }^{\circ} \mathrm{C}$, while pure $\mathrm{Ni}$ catalysts produce multilayer films at the same temperature.

In this study, we compared graphene grown on two $50 \mathrm{~nm}$ thick catalysts: (1) pure $\mathrm{Ni}$ and (2) a $\mathrm{Ni} / \mathrm{Cu}$ catalyst thin film (48 $\mathrm{nm} \mathrm{Ni}$ with $2 \mathrm{~nm} \mathrm{Cu}$ at the surface) which alloys upon heating. The metals were DC sputtered on $\mathrm{Si} / \mathrm{SiO}_{2}$ wafers and subjected to a single growth recipe in an inductively-coupled plasma enhanced CVD reactor at $500{ }^{\circ} \mathrm{C}$.

Raman spectroscopy was used to analyze the properties of graphene films synthesized on each catalyst. The intensity ratio of the $2 \mathrm{D}$ peak to the $\mathrm{G}$ peak, $\mathrm{I}_{2 \mathrm{D} / \mathrm{G}}$, is an indicator of layer number, where an $\mathrm{I}_{2 \mathrm{D} / \mathrm{G} \text { of }}$ 1.00-2.00 represents bi-/few-layer graphene and $<1.00$ represents multilayer. Fig. 1 (a) displays an $\mathrm{I}_{2 \mathrm{D} / \mathrm{G}}$ map of graphene synthesized on the $\mathrm{Ni} / \mathrm{Cu}$ alloy with representative Raman spectra of bi-, few-, and multilayer regions shown in Fig. 1 (b). It was observed that graphene synthesized on pure Ni produced 100\% multilayer coverage while $73 \%$ of graphene synthesized on the $\mathrm{Ni} / \mathrm{Cu}$ alloy was bi-/few-layer.

To characterize the effects of catalyst morphology on graphene quality, we acquired SEM images and EBSD data of as-grown graphene on each catalyst (Table 1). Fig. 2 (a) and (c) show SEM images of graphene on $\mathrm{Ni}$ and $\mathrm{Ni} / \mathrm{Cu}$ respectively. The EBSD images of these two samples are shown in Fig. 2 (b) and (d), respectively with an inverse pole figure legend shown in Fig. 2 (e). The results indicate that grains on $\mathrm{Ni} / \mathrm{Cu}$ and pure $\mathrm{Ni}$ catalyst are similar in size, with $\mathrm{Ni} / \mathrm{Cu}$ catalyst grains slightly larger on average. Inverse Pole Figure $\mathrm{Z}$ maps suggest that the crystalline orientation of the catalyst grains is randomly distributed in both samples. To characterize the $\mathrm{Ni} / \mathrm{Cu}$ elemental distribution within the catalyst, energy dispersive X-Ray spectroscopy (EDS) was performed in a TEM. Fig. 3 shows a line scan across grain morphology and boundaries of the samples. The spectra exhibit a consistent $\mathrm{Ni}$ to $\mathrm{Cu}$ ratio, indicating uniform alloying throughout the catalyst.

Our results indicate that $\mathrm{Ni} / \mathrm{Cu}$ alloying occurs evenly in the catalyst, and that both grainsize and orientation are is not significantly altered during and after the graphene growth compared to pure Ni. This suggests that the $\mathrm{Ni} / \mathrm{Cu}$ alloy enables graphene layer suppression primarily through reduction in carbon solubility, rather than through change in physical morphology [3]. 
References:

[1] Yun Sung Woo et al., Carbon 64 (2013), p. 315.

[2] Xin Bian et al, RCS Advances 6 (2017), p. 74937.

[3] The authors acknowledge support from the National Science Foundation (No. 1560383), Oregon Metals Initiative (No. 1711994), Intel Corporation, and PSU Undergraduate Research and Mentorship Program.
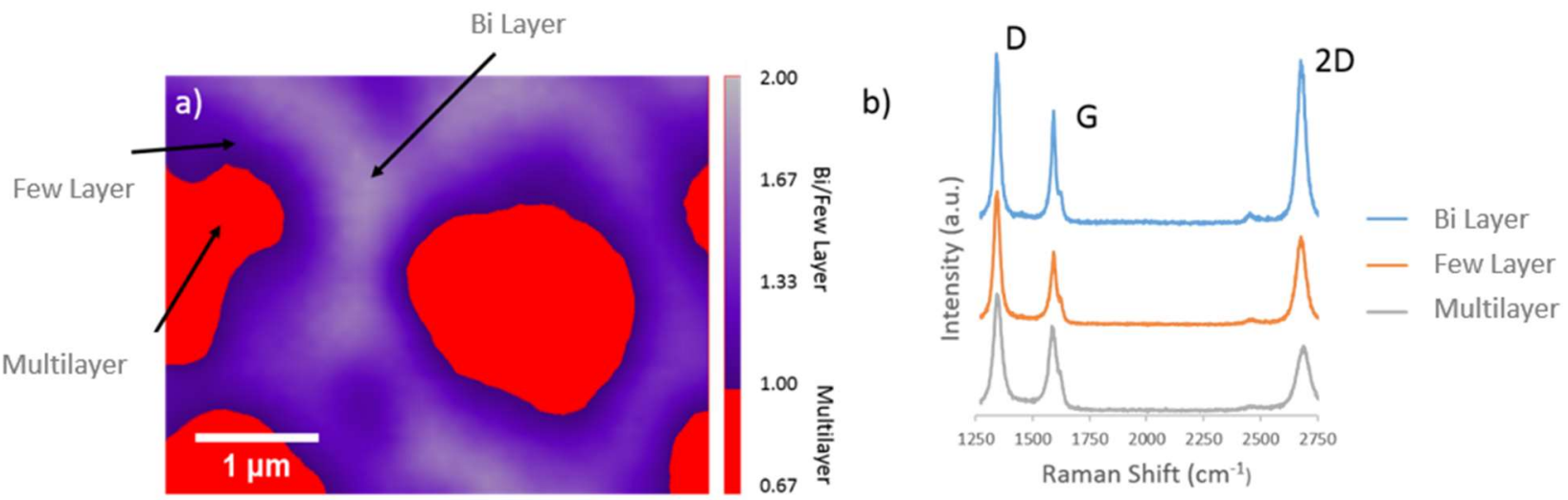

Figure 1. a) $\mathrm{I}_{2 \mathrm{D} / \mathrm{G}}$ Raman map of graphene grown on $\mathrm{Ni} / \mathrm{Cu}$, with bi/few layer gradient and multilayer in red. Example spectra location indicated. b) Representative Raman spectra.

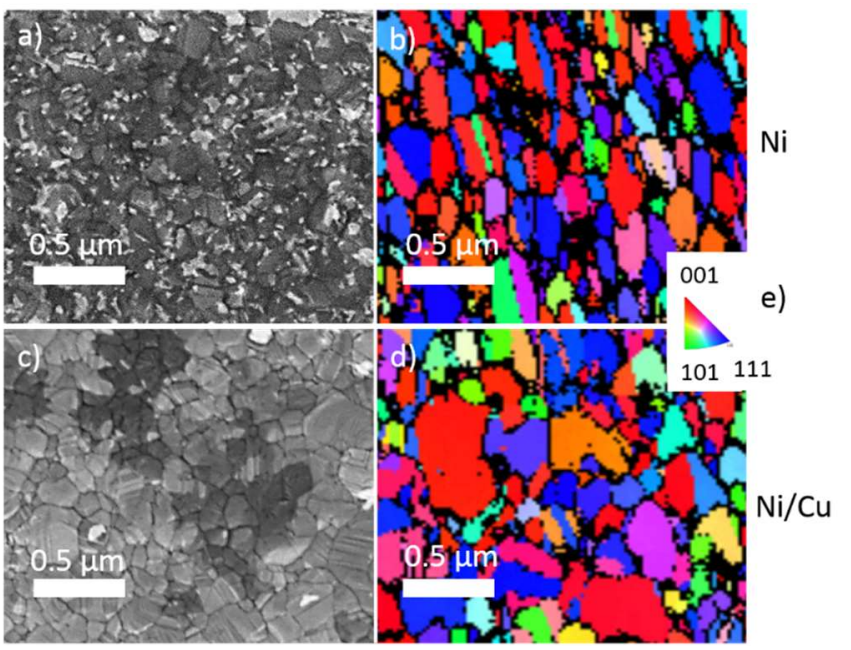

Figure 2. a) and c) SEM images of asgrown graphene on $\mathrm{Ni}$ and $\mathrm{Ni} / \mathrm{Cu}$ catalysts, respectively. b) and d) EBSD Inverse Pole Figure $\mathrm{Z}$ map of $\mathrm{Ni}$ and $\mathrm{Ni} / \mathrm{Cu}$ catalyst, respectively. e) EBSD Inverse Pole figure legend

Figure 3. STEM image of as-grown $\mathrm{Ni} / \mathrm{Cu}$ catalyst with EDS line scan location (in black) and overlaid $\mathrm{X}$-ray counts of $\mathrm{Ni}, \mathrm{Cu}$, and normalized $\mathrm{Cu}$

\begin{tabular}{|c|c|c|c|}
\hline Catalyst Type & $\mathrm{Ni}$ & $\mathrm{Ni} \mathrm{Cu}$ & Difference \\
\hline $\begin{array}{c}\text { Primary } \\
\text { Crystal Orientation }\end{array}$ & \multicolumn{3}{|c|}{ Area } \\
\hline$(001)$ & $24.16 \%$ & $32.38 \%$ & $8.22 \%$ \\
\hline$(101)$ & $3.21 \%$ & $5.01 \%$ & $1.80 \%$ \\
\hline$(111)$ & $17.93 \%$ & $23.94 \%$ & $6.01 \%$ \\
\hline Other & $54.70 \%$ & $38.67 \%$ & $16.03 \%$ \\
\hline Grain Size & \multicolumn{3}{|c|}{ Area } \\
\hline$>0.060 \mu \mathrm{m}^{2}$ & $25.17 \%$ & $38.59 \%$ & $13.42 \%$ \\
\hline$<0.060 \mu \mathrm{m}^{2}$ & $74.83 \%$ & $61.41 \%$ & $13.42 \%$ \\
\hline Average Area $\mu \mathrm{m}^{2}$ & 0.0220 & 0.0249 & 0.0049 \\
\hline
\end{tabular}

Table 1. Comparison of as-grown $\mathrm{Ni}$ and $\mathrm{Ni} / \mathrm{Cu}$ catalyst composition, crystal orientation and grain size.

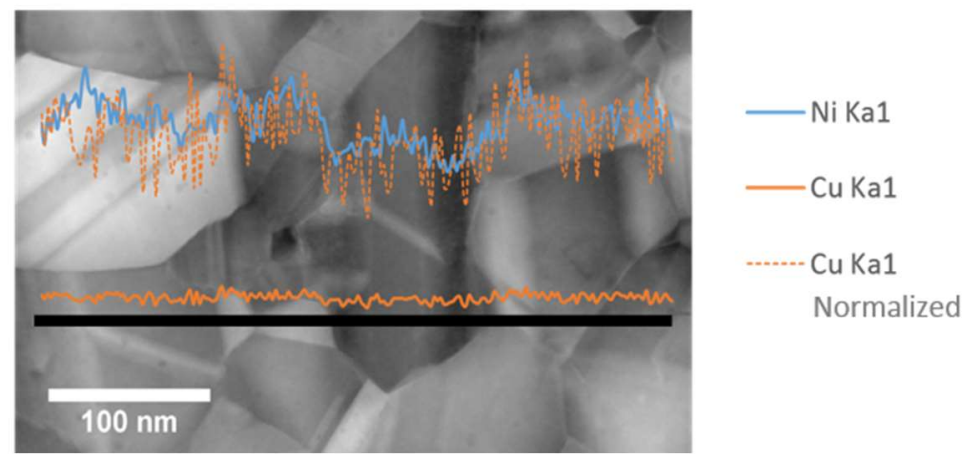

